\title{
FABRICATION AND CHARACTERIZATION OF HIGH TEMPERATURE RESIN/CARBON NANOFIBER COMPOSITES
}

\author{
Sayata Ghose, ${ }^{1}$ Kent A. Watson, ${ }^{2}$ Dennis C. Working, ${ }^{3}$ Jim M. Criss, ${ }^{4}$ Emilie J. Siochi, ${ }^{3}$ John W. \\ Connell $^{3}$ \\ ${ }^{1}$ National Research Council Research Associate located at NASA LaRC, Hampton, VA 23681 \\ ${ }^{2}$ National Institute of Aerospace, 100 Exploration Way, Hampton, VA 23666 \\ ${ }^{3}$ NASA Langley Research Center, Hampton, VA 23681-2199 \\ ${ }^{4} \mathrm{M} \& \mathrm{P}$ Technologies, Inc. Marietta, GA 30068
}

\begin{abstract}
As part of ongoing efforts to develop multifunctional advanced composites, blends of PETI-330 and carbon nanofibers (CNF) were prepared and characterized. Dry mixing techniques were employed and the effect of CNF loading level on melt viscosity was determined. The resulting powders were characterized for degree of mixing, thermal and rheological properties. Based on the characterization results, samples containing 30 and $40 \mathrm{wt} \%$ CNF were scaled up to $\sim 300 \mathrm{~g}$ and used to fabricate moldings $10.2 \mathrm{~cm} \times 15.2 \mathrm{~cm} \times 0.32 \mathrm{~cm}$ thick. The moldings were fabricated by injecting the mixtures at $260-280{ }^{\circ} \mathrm{C}$ into a stainless steel tool followed by curing for $1 \mathrm{~h}$ at $371^{\circ} \mathrm{C}$. The tool was designed to impart high shear during the injection process in an attempt to achieve some alignment of CNFs in the flow direction. Moldings were obtained that were subsequently characterized for thermal, mechanical and electrical properties. The degree of dispersion and alignment of CNFs were investigated using high-resolution scanning electron microscopy. The preparation and preliminary characterization of PETI-330/CNF composites will be discussed.
\end{abstract}

Keywords: phenylethynyl terminated imides, nanocomposites, moldings, ball-milling

This paper is work of the U. S. Government and is not subject to copyright protection in the U.S. 


\section{INTRODUCTION}

Carbon nanofibers (CNF) are widely used as reinforcements for polymers in numerous hightechnology applications by virtue of their excellent electrical and thermal properties and their high specific tensile modulus and strength [1]. Other benefits include improved heat distortion temperatures and increased electromagnetic shielding. CNFs have been used as reinforcements for various thermoplastics like polyethylene [2], polypropylene [3,4], polycarbonate [5], nylon [6] and poly (methyl methacrylate) [7]. CNFs have a wide range of morphology, from disordered bamboo-like structures [8] to highly graphitized “cup-stacked” structures where conical shells are nested within one another [9]. These fibers are produced by a catalytic vapor deposition process and are highly graphitic in structure and more economically attractive for use in electronics, automotive and aerospace industries than carbon nanotubes (lower manufacturing costs).

Structural composite applications on advanced aerospace vehicles such as high speed aircraft and reusable launch vehicles require high temperature, high performance resins. Major applications of fiber-reinforced composites appear in aerospace and military fields due to their low density, mechanical properties and high temperature performance. Carbon fiber composites have become the primary material in many wings, fuselage and empennage components as well as secondary structures of many commercial aircraft. High temperature organic matrix composites are also finding applications in missile structures and jet engines.

Future applications for organic matrix composites are becoming more demanding in terms of the desired combination of properties. In addition to processability, mechanical, and thermal performance other properties to consider include electromagnetic interference (EMI) and radio frequency interference (RFI) shielding. Polymer-matrix composites containing conductive fillers are a potential means of achieving an attractive combination of properties for aerospace applications. The conductive fillers are preferably small in size (skin effect), have high electrical conductivity (for shielding by reflection) and high aspect ratio (lower percolation threshold) [10].

Due to their excellent physical and mechanical properties, aromatic polyimides have emerged as one of the leading candidates for aerospace applications. Controlled molecular weight imide oligomers containing phenylethynyl groups (phenylethynyl terminated imide (PETI), e.g. PETI330) exhibit exceptional processability during fabrication of neat resin moldings, bonded panels and composites. PETI-330 is a low molecular weight imide oligomer with a low, stable melt viscosity and a glass transition temperature of around $330{ }^{\circ} \mathrm{C}$ after curing for $1-2 \mathrm{hr}$ at $371{ }^{\circ} \mathrm{C}$. It was designed specifically for resin transfer molding (RTM) and resin infusion (RI) processing and has been used for making composites by RTM, vacuum-assisted RTM (VARTM) and RI. PETI-330 laminates exhibit excellent thermal and mechanical properties [11,12]. PETI-330 laminates have exhibited excellent retention of room temperature open hole compression strength and short beam shear strength after aging $1000 \mathrm{hr}$ at $288^{\circ} \mathrm{C}$. [13].

In this study, CNF (Pyrograf III $^{\circledR}$ ) was selected as the conductive and mixed with PETI-330 at various loading levels. Ball-milling was selected as a means of dry-mixing the two components. Ball-milling is a mechanical process that leads to local generation of high pressure as a result of the collision between the grinding media [14]. This method has been used to obtain nano-barrels from cup-stacked carbon nanotubes [15], transform nanotubes into nanoparticles (ellipsoidal and 
spherical) [16], generate nanostructures from graphite [17 - 18] and shorten the lengths of nanotubes [19 - 20]. Polyethylene terephthalate (PET) can be compounded with various grades (5 wt \%) of carbon nanofibers (CNF) by ball-milling [21] followed by extrusion or melt mixing.

In the current study, ball-milled PETI-330/CNF (Pyrograf III ${ }^{\circledR}$ ) powder was injected under pressure into a tool and cured under pressure to obtain moldings of specific dimensions. Experiments were carried out at various CNF loadings and the effect on melt viscosity and processability was determined. Based on melt viscosity data from a parallel plate rheometer, an optimum loading providing substantial conductivity without compromising processability was selected.

Melt extrusion was also investigated as a means of assessing processing characteristics. The extrusion process involves high shear mixing which helps to disentangle CNFs and disperse them uniformly within the matrix. The process of extruding the nanocomposite through a suitable die and subsequent drawing led to continuous ribbons of nanocomposites that were further processed into laminates with substantial orientation of the nanofibers in the flow direction.

The samples were characterized using differential scanning calorimetry, thermogravimetric analysis, high resolution scanning electron microscopy, Raman spectroscopy, mechanical properties, thermal conductivity and electrical resistivity. The preparation, characterization and fabrication of PETI-330/CNF (Pyrograf III ${ }^{\circledR}$ ) are presented herein.

\section{EXPERIMENTAL}

2.1 Materials Anhydrous $N$-methyl-2-pyrrolidinone (99.8\%, NMP) was obtained from Aldrich Chemical Co. PETI-330 was obtained from JFC Technologies, Bound Brook, NJ. Pyrograf ${ }^{\circledR}$-III CNFs were obtained from Applied Sciences, Inc., Cedarville, $\mathrm{OH}$. The fine, highly graphitic CNFs had diameters between 70 and $200 \mathrm{~nm}$ and a length between 50 and $100 \mu \mathrm{m}$. All materials were used as received.

2.2 Preparation of PETI-330 with CNF: dry mixing Dry mixing of PETI-330 and CNFs was carried out in alumina-fortified porcelain jars using cylindrically shaped zirconia grinding media $(9.5 \mathrm{~mm}$ x $9.5 \mathrm{~mm})$. The jars were placed on rollers and rotated at $120 \mathrm{rpm}$ for $48 \mathrm{~h}$. Initially mixing was done on a small scale using jars with 1.9 L capacity. Mixtures containing 10, 30, 40 and $50 \mathrm{wt} \%$ CNFs were prepared. Based on the melt rheology and other characterization, two samples were chosen for scale-up that was performed using a $5.7 \mathrm{~L}$ jar. After $48 \mathrm{~h}$ of mixing, the grinding media was separated from the powder using a sieve and the powder was collected. A typical recovery yield was about $90 \%$ of the total weight. Loss of material was due to adhesion of powder to walls of the jar and grinding media.

2.3 Preparation of PETI-330 with 30 \% (wt/wt) CNF: solution method Into a $100 \mathrm{~mL}$ three necked round bottom flask equipped with a mechanical stirrer and nitrogen inlet were placed PETI-330 (11.00 g) and NMP (40 g). The mixture was heated to $120{ }^{\circ} \mathrm{C}$ and stirred until all solids dissolved. CNF (1.10 g) was added followed by additional NMP (10 g). The black mixture was stirred at $\sim 70{ }^{\circ} \mathrm{C}$ for $5 \mathrm{~h}$. PETI-330/CNF solid was isolated by pouring the reaction mixture 
into water to precipitate a dark grey solid. PETI-330/CNF solid was washed several times in hot water and dried at $110{ }^{\circ} \mathrm{C}$ overnight. The mixture was then dried in a forced air oven at $150{ }^{\circ} \mathrm{C}$ for $4 \mathrm{~h}$.

2.4 Composite specimens of PETI-330/MWCNT An Invar ${ }^{\circledR}$ tool designed to provide shear during injection was used in the fabrication of moldings. Approximately $300 \mathrm{~g}$ of PETI$330 / \mathrm{CNF}$ sample was degassed in the injector by heating to $280^{\circ} \mathrm{C}$ and holding for $1 \mathrm{~h}$ prior to injection. The degassing step is generally required in RTM primarily to remove moisture and air from the resin. After the resin was injected at $288{ }^{\circ} \mathrm{C}$ at a rate of $200 \mathrm{~mL} / \mathrm{min}$, the tool was clamped in a press in order to assure adequate sealing and held at a minimum pressure of 1.38 $\mathrm{MPa}$, heated to $371^{\circ} \mathrm{C}$ and held at this temperature for $1 \mathrm{~h}$. The plaques were then cooled in the mold.

2.5 Other characterization Differential scanning calorimetry (DSC) was performed on the powder samples obtained from ball-milling using a Shimadzu DSC-50 thermal analyzer at a heating rate of $20{ }^{\circ} \mathrm{C} / \mathrm{min}$ with the glass transition temperature $\left(\mathrm{T}_{\mathrm{g}}\right)$ taken as the mid-point of inflection of the differential heat flow $(\Delta \mathrm{H})$ versus temperature curve. Samples were cured in a sealed aluminum pan at $371^{\circ} \mathrm{C}$ for $1 \mathrm{~h}$, cooled to room temperature and then heated again to 450 ${ }^{\circ} \mathrm{C}$ to determine the $\mathrm{T}_{\mathrm{g}}$. Thermogravimetric analyzer (TGA) measurements in air (flow rate of 50 $\mathrm{mL} / \mathrm{min}$ ) were performed on powder samples using an Auto TGA 2950HR (TA Instruments, $\mathrm{DE}$ ). The samples were heated at $20^{\circ} \mathrm{C} / \mathrm{min}$ to $100{ }^{\circ} \mathrm{C}$, held for $0.5 \mathrm{~h}$ to drive off any moisture, and heated to $600{ }^{\circ} \mathrm{C}$ at a rate of $2.5^{\circ} \mathrm{C} / \mathrm{min}$. Dynamic rheological measurements were obtained using an Advanced Rheometric Expansion System (ARES) Rheometer from Rheometrics, Inc. Measurements were carried out under nitrogen in an oscillatory shear mode using parallel plate geometry (30 mm diameter) at a heating rate of $4{ }^{\circ} \mathrm{C} / \mathrm{min}$ from 100 to $371^{\circ} \mathrm{C}$. The top plate was oscillated at a variable strain and a fixed angular frequency of $100 \mathrm{rad} / \mathrm{s}$ while the lower plate was attached to a transducer that recorded the resultant torque. High-resolution scanning electron microscope (HRSEM) images were obtained using a Hitachi S-5200 field emission scanning electron microscope (FE-SEM) equipped with a "through-the-lens" secondary electron detector operating at or below $1 \mathrm{kV}$. Composite images were obtained in low voltage mode in order to set up a stable local electric field on the sample while minimizing beam-induced damage. Both the powder as well as the sample obtained from the ARES were scanned. Raman spectroscopy was carried out using a Thermo Nicolet Almega Dispersive Raman spectrometer equipped with a 785 $\mathrm{nm}$ laser. The pinhole was $25 \mu \mathrm{m}$ and the spectral range was $3434-72 \mathrm{~cm}^{-1}$. Powder samples were also extruded through a Laboratory Mixing Extruder (LME, Dynisco, MA). The temperature of the mandrel was set at $200-210{ }^{\circ} \mathrm{C}$ and the temperature of the die $(1 \mathrm{~mm}$ diameter) was set at $230{ }^{\circ} \mathrm{C}$. The axial gap size was set at $0.64 \mathrm{~mm}$ and rotor speed was $270 \mathrm{rpm}$. Elemental analysis of the neat CNFs was performed by Desert Analytics (Tucson, AZ) by combustion with the aid of tungsten trioxide $\left(\mathrm{WO}_{3}\right)$. Surface and volume resistivities were measured using a Prostat ${ }^{\circledR}$ PRS-801 Resistance System with a PRF-911 Concentric Ring Fixture per ASTM D-257 and reported as an average of three readings. Readings were taken before and after the plaques were polished using a Ecomet-4 Variable Speed Grinder-Polisher. A load of $9.07 \mathrm{~kg}$-force and sanding grids of 60 and 100 were used for polishing. Surface resistance was also measured using a Keithley Sub-Femtoamp Remote Source Meter (Model 6430). Samples 
were mounted on a Summit 11000/12000 B-Series Probe Station (Cascade Microtech). Distance between the two probes was $0.18 \mathrm{~cm}$ and a current of $1 \mu \mathrm{A}$ was applied.

Thermal conductivity of the plaques was measured using a Netzsch LFA 447 NanoFlash according to ASTM E1461. Samples sizes of $1 \mathrm{~cm} \times 1 \mathrm{~cm}$ were sprayed with a thin layer of graphite (for uniform thermal adsorption), which may be easily rinsed away by solvent (e.g., methanol). Pyrex (TC $1.09 \mathrm{~W} / \mathrm{mK}, \mathrm{Cp} \sim 0.76 \mathrm{~J} / \mathrm{gk}$ ) was used as the reference. Hardness tests were performed on the injection molded plaques using a Wilson Rockwell Hardness Tester (Series 2000). A $1.5875 \mathrm{~mm}$ diameter hardened steel ball was used for Test HRT15 with an initial load of $3 \mathrm{~kg}$ and a total load of $15 \mathrm{~kg}$. Hardness of the neat resin and composite plaques was also measured using a Shore D durometer according to ASTM D2240 with the plaques being treated as hard plastics. Tensile properties were evaluated using a Sintech $2 \mathrm{~W}$ and Testworks 4 software with a load cell of $1.334 \mathrm{kN}$ (300 lb-force), crosshead speed of 5.08 $\mathrm{mm} / \mathrm{min}$ and gauge length of $22 \mathrm{~mm}$. Samples were prepared according to specifications of ASTM D1708 and were machined using a Bengal 20 x 40 Water Jet (Flow Corp.).

\section{RESULTS AND DISCUSSION}

CNFs (30 wt \%) were added to PETI-330 by two different methods. The first was dry mixing via ball-milling and in the second method the fibers were added to a solution of PETI-330 in NMP. Melt viscosity at $280{ }^{\circ} \mathrm{C}$ of the sample prepared by the solution method was at least one order of magnitude higher than that prepared by ball-milling. The higher viscosity exhibited by the sample prepared in solution was also evident in extrusion experiments. This sample could not be extruded into continuous strands whereas the sample prepared by ball milling could. Hence the ball-milled sample was chosen for further processing.

3.1 HRSEM images of ball-milled PETI-330/ CNF samples: CNFs tend to form agglomerates which can be minimized by the appropriate application of high shear during mixing. Melt mixing of CNFs with various thermoplastics like polyethylene [2], polypropylene [3,4], polycarbonate [5], nylon [6], poly (methyl methacrylate) [7], poly (ether ether ketone) [22], polyamide [23] and epoxies [24] have been successful and SEM images showing good dispersion of the fibers have been obtained [1, 21]. Typically all polymers are insulating and exposure to the electron beam would cause them to burn. In this work, HRSEM images could be obtained for both the powder samples and samples from the ARES even at a loading level of $10 \mathrm{wt} \%$, an indication of a reasonably good dispersion of nanofibers in the polymer matrix to form a conductive network.

Figure 1 shows HRSEM pictures of neat CNFs as well as powdered PETI-330/CNF samples obtained after ball-milling. Typical diameters of individual fibers vary from $50-200 \mathrm{~nm}$ according to the manufacturer but those observed in this study were $100-250 \mathrm{~nm}$. Figure 1(b) illustrates the stacked cup structure of the CNF as concentric layers. As evident from Figures 1 (c) and (d), there is an abundance of CNF between polymer particles at various loading levels. Figures 1 (e) and (f) show images of samples after testing in the rheometer. CNFs are well dispersed in the polymer matrix (Figure 1e) and at higher magnifications, the fibers do not exhibit any damage as a result of the ball-milling or the ARES experiment (Figure 1f). The fibers appear to have a bright coating in the HRSEM images which is an indication of a less conductive polymer coating on the nanofiber surface. The places where the fibers enter the polymer matrix 
have a dark circle around them which is caused by a difference in conductivity between fibers and matrix.

3.2 Melt viscosity of ball-milled PETI-330/ CNF samples: The complex viscosity of neat as well as CNF-loaded PETI-330 samples was determined from the rheometer (ARES) experiments. Discs of the samples were prepared by compression molding approximately $0.75 \mathrm{~g}$ of sample at room temperature and subsequently inserting in the test chamber at $100{ }^{\circ} \mathrm{C}$. Specimens were heated to $280{ }^{\circ} \mathrm{C}$ at a rate of $4{ }^{\circ} \mathrm{C} / \mathrm{min}$ and held at $280{ }^{\circ} \mathrm{C}$ for $2 \mathrm{~h}$ to assess melt stability. Heating was then continued at the same rate to $371{ }^{\circ} \mathrm{C}$ and held for $100 \mathrm{~s}$. Figure 2 shows melt viscosity curves of neat and CNF loaded samples. Melt viscosity of samples at 280 ${ }^{\circ} \mathrm{C}$ is important as the resin is injected at this temperature. The neat resin has a low melt viscosity, between 5 and 10 poise (P). At $280{ }^{\circ} \mathrm{C}$ and a fixed strain rate, viscosity shows an increasing slope. The phenylethynyl groups do not readily react at this temperature so no significant curing of the resin occurs. This has been tested using DSC when no cured $\mathrm{T}_{\mathrm{g}}$ was obtained on samples held at $280{ }^{\circ} \mathrm{C}$ for $2 \mathrm{~h}$. As anticipated, when heating is resumed after $2 \mathrm{~h}$, viscosity shows a decrease with increasing temperature. When the temperature reaches $>300{ }^{\circ} \mathrm{C}$, the phenylethynyl groups start to react and consequently viscosity increases. For the 10 wt $\%$ CNF filled samples, the melt viscosity is close to that of the neat resin but increases with an increase in the CNF wt \%. An exception is the $50 \mathrm{wt} \%$ CNF-filled PETI-330 where the melt viscosity drops to a value lower than that of the 30 and $40 \mathrm{wt} \% \mathrm{CNF}$. The reason for this is not clear, but it is possible that at higher loadings the CNFs are acting as a lubricant and thus preventing proper friction with the plates of the rheometer causing the viscosity to appear lower. Another possibility is that at higher loadings the dispersion is less uniform leading to agglomerates of CNFs and an effectively lower viscosity. A similar behavior has also been observed in our experiments with PETI-330/MWNTs [25]. The melt viscosity for $40 \mathrm{wt} \%$ CNF is $\sim 4800 \mathrm{P}$ which is lower than the tolerable value of $\sim 25,000 \mathrm{P}$ for injection molding thus making loadings up to $40 \mathrm{wt} \%$ suitable for scale-up.

3.3 Raman Spectroscopy: Like MWNTs, the Raman spectra of CNFs typically exhibit two optically active phonon modes [26, 27]. The first one is an optically active in-plane stretching $\mathrm{E}_{2 \mathrm{~g}}$ mode, the so-called graphite mode, popularly termed as the " $\mathrm{G}$ " band with a peak around $1600 \mathrm{~cm}^{-1}$. The second strong band around $1350 \mathrm{~cm}^{-1}$ is referred to as the "D" band and has been attributed to disordered graphitic structures. During the manufacturing of CNFs disordered carbonaceous compounds, including amorphous carbon, are produced and these appear in the Dband. As seen in Figure 3, for the neat PETI-330, no feature is observed from $1000-2000 \mathrm{~cm}^{-1}$. At lower concentrations of CNFs, both the $G$ and $D$ bands are completely masked by the spectrum of the polymer but bands are observed at concentrations of $30 \%$ or higher and the intensities of both bands increase with increasing nanofiber concentration.

3.4 Other characterization: Elemental analysis of CNFs showed a 1.5 wt \% iron content and $\sim 96$ wt \% carbon content. The $\mathrm{T}_{\mathrm{g}}$ of neat PETI-330 was $326^{\circ} \mathrm{C}$ with only a small change in $\mathrm{T}_{\mathrm{g}}$ observed by adding nanofibers with a maximum $\mathrm{T}_{\mathrm{g}}$ of $332{ }^{\circ} \mathrm{C}$ at $50 \mathrm{wt} \% \mathrm{CNFs}$ addition (Table 1). 
3.5 Extrusion of filled nanocomposites: The 30 and $40 \mathrm{wt} \%$ samples were scaled up for extrusion. Figure 4 shows the viscoelastic properties of neat and CNF-filled resin. Figure 4(a) shows a trend of increasing storage modulus values for all samples except the $50 \mathrm{wt} \% \mathrm{CNF}-$ filled PETI-330, even at high frequencies. However, for the $50 \mathrm{wt} \%$ sample, the value has already reached a plateau region indicating the presence of a physical network. This would not favor processing and hence the 50 wt \% CNF-filled PETI-330 was not scaled up. As evident from Figure 4(b), linear regression shows the viscosity of neat polymer and CNF-filled resin to follow the power law equation given by $\eta=m \dot{\gamma}^{n-1}$ where $\dot{\gamma}$ is the shear rate, $m$ is the consistency and $n$ is the power law index. The power law index decreases with increasing CNF content. Additionally, the scale-up of 30 and $40 \mathrm{wt} \%$ CNF samples shows a decrease in viscosity.

Neat resin and PETI-330/CNF samples were extruded through a LME. The temperature of the mandrel was between 210 and $215{ }^{\circ} \mathrm{C}$ while the die temperature was set at $230{ }^{\circ} \mathrm{C}$. Due to the low melt viscosity of the neat resin it was difficult to obtain continuous fibers even when the die temperature was raised to $300{ }^{\circ} \mathrm{C}$. However, extrusion at temperatures up to $300{ }^{\circ} \mathrm{C}$ did not affect the melt viscosity of the resin indicating that no crosslinking (i.e. reaction of the phenylethynyl groups) was taking place [25]. For both the 30 and $40 \mathrm{wt} \%$ CNF samples, fibers of $\sim 1 \mathrm{~m}$ length were extruded at a uniform output rate. In the case of the $50 \mathrm{wt} \% \mathrm{CNF}$ sample, difficulties were encountered during feeding and the rotor temperature rose to $245{ }^{\circ} \mathrm{C}$ due to frictional heat build-up resulting in brittle fibers possibly due to agglomeration of the CNFs. One significant observation was the alignment of nanofibers as a result of extrusion. Figure 5(a) shows a HRSEM image of the surface of the $30 \mathrm{wt} \%$ extruded fiber. It is apparent that most of the fibers are aligned in the direction of extrusion. The orientation of the fibers is more obvious at the end of the fibers as seen in Figure 5(b). It was observed that a majority of CNFs are unidirectionally aligned within the polymer matrix.

3.6 Characterization of Nanocomposite Plaques: PETI-330/CNF moldings, $10.2 \mathrm{~cm}$ x $15.2 \mathrm{~cm}$ x $0.32 \mathrm{~cm}$ and containing 30 and $40 \mathrm{wt} \%$ CNFs, were prepared by injecting the samples into a specially designed tool (Figure 6) and curing at $371^{\circ} \mathrm{C}$ for $1 \mathrm{~h}$. The moldings were subsequently characterized.

HRSEM images of the plaques show a reasonably uniform distribution of CNFs within the polymer matrix (Figure 7). However, only in some instances was an alignment of the CNFs in the flow direction observed (Figure 7b).

Hardness is defined as the property of a material that enables it to resist plastic deformation, typically by penetration. The hardness testing of plastics is most commonly measured by the Rockwell hardness test or Shore (Durometer) hardness test and these methods measure the resistance of the plastic toward indentation [28]. Both Rockwell and Shore D hardness were determined for the PETI-330/CNF plaques and the values are given in Table 2. The Rockwell hardness number (HR) of a material is given by the equation

$$
\mathrm{HR}=E-e
$$

where $e$ is the permanent increase in depth of penetration due to major load, measured in units of $0.001 \mathrm{~mm}$ and $E$ is a constant of 100 units for diamond and ball indenters. In this case, the CNFfilled PETI-330 samples showed a lower hardness value compared to the neat resin. A lower HR 
value indicates a greater depth of effective penetration of the indenter or an enhanced plastic deformation of the material.

Surface and volume resistivities of the plaques were measured using Prostat ${ }^{\circledR}$ PRS-801 Resistance System (units: $\Omega /$ sq) per ASTM D-257 (see Table 3). Polishing the surface of the plaques served to decrease the resistivity. As expected the neat resin was electrically insulating and with the addition of CNFs, resistivity decreased. For ESC dissipation to occur, the surface resistivity should be typically between $10^{6}$ and $10^{10} \Omega /$ sq [29]. Surface resistivity (units: $\Omega / \mathrm{cm}$ ) was measured by a two-point probe system. Here too, the neat samples did not show any conductivity whereas the CNF-filled samples were in the ESC dissipation range. However, it is noticed that the $40 \mathrm{wt} \%$ sample showed a higher resistivity than the $30 \mathrm{wt} \%$ sample. Mapping the resistivity of the $40 \mathrm{wt} \%$ sample using the two-point probe showed one-third of the sample (near the exit port of the mold) to be insulative. At higher loadings it is likely that CNFs tended to nest together and did not flow uniformly in the polymer matrix leading to non uniform dispersion and consequently non uniform resistivity in the plaque.

Thermal conductivity was measured using the Nanoflash instrument according to ASTM E-1461. The instrument allows direct measurement of thermal diffusivity $(\alpha)$ and a comparative measurement of heat capacity (Cp). The thermal conductivity $(\lambda)$ is then calculated as $\lambda=\alpha \rho$ $C p$. Table 4 shows the thermal conductivity data of the neat and CNF-filled samples. With a loading of $30 \mathrm{wt} \%$, the conductivity has improved 250 \% while with $40 \mathrm{wt} \%$ loading the improvement is $300 \%$. It is evident that nanofibers are forming an effective network in the polymer matrix which efficiently conducts heat.

Tensile properties were evaluated using a load cell of $1.334 \mathrm{kN}$ (300 lbf), a crosshead speed of $5.08 \mathrm{~mm} / \mathrm{min}$ and a gauge length of $22 \mathrm{~mm}$. Investigations on the physical appearance of samples were carried out using optical microscopy (Olympus BH-2) at a magnification of 5x. Figure 8 is representative of most samples and shows voids. These voids may be due to volatilization of low molecular weight oligomers within the matrix. PETI-330 was developed as a composite matrix resin and no work has been conducted to optimize the fabrication of neat resin moldings. As a result, during tensile testing the voids act as defect sites that initiate premature mechanical failure, resulting in low mechanical properties and rendering the data unusable. These measurements were done both in the flow direction and normal to the flow direction. Based on defects in these samples, this mechanical data is inconclusive.

\section{SUMMARY}

The effect of CNF loading on the processing characteristics of PETI-330 was investigated. Loading levels up to $40 \%$ by weight could be achieved without compromising the processability. Select samples were scaled up for processing and continuous strands of nanocomposites were extruded. These strands showed significant alignment along the direction of extrusion. Plaques were prepared by injecting samples into a specially designed tool followed by curing. Hardness measurements indicate enhanced plastic deformation in the samples. As expected PETI330 ? CNF plaques have a lower electrical resistivity compared to the neat resin. Incorporation of CNFs also improved the thermal conductivity of the samples two- to threefold at 30 and $40 \%$ loading, respectively. However, molded samples contained voids and mechanical properties were 
inconclusive due to these defects. Further efforts will focus on optimization of the molding process to fabricate void free plaques.

\section{Acknowledgement}

The authors express their sincere gratitude to Tom Hughes of Applied Sciences, Inc. Cedarville, $\mathrm{OH}$ for supplying the CNFs. The thermal conductivity measurements by Professor Ya-Ping Sun of Clemson University and the 2 point probe electrical resistivity measurements by Dr. Keun J. Sun of the National Institute of Aerospace are greatly appreciated. 


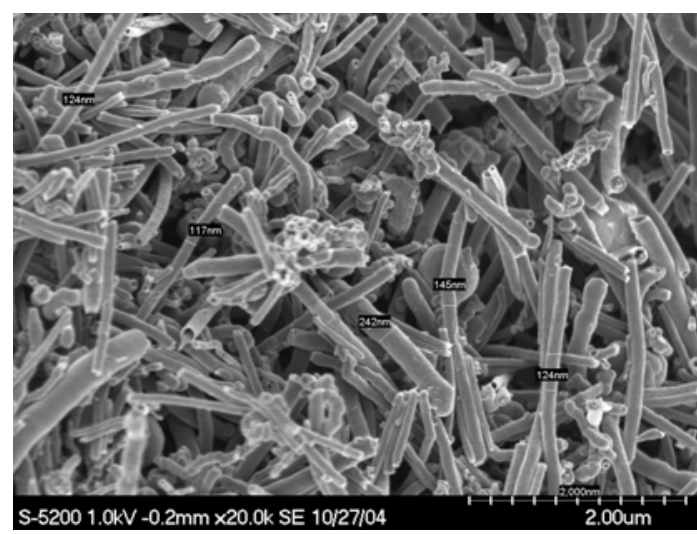

(a) Neat CNF

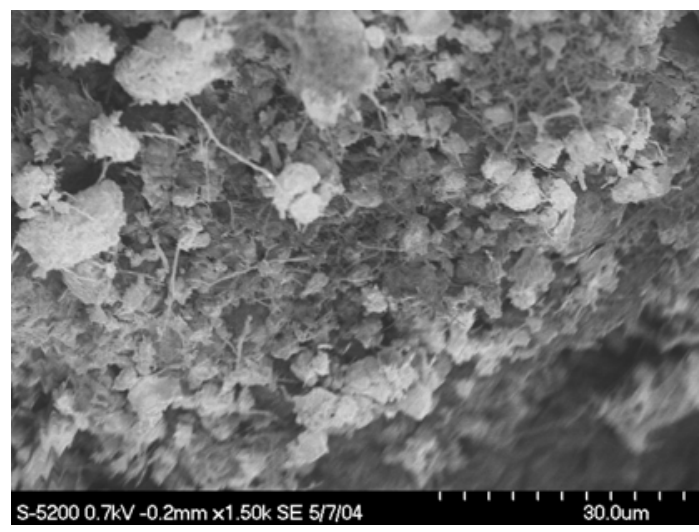

(c) PETI-330/50 wt\% CNF

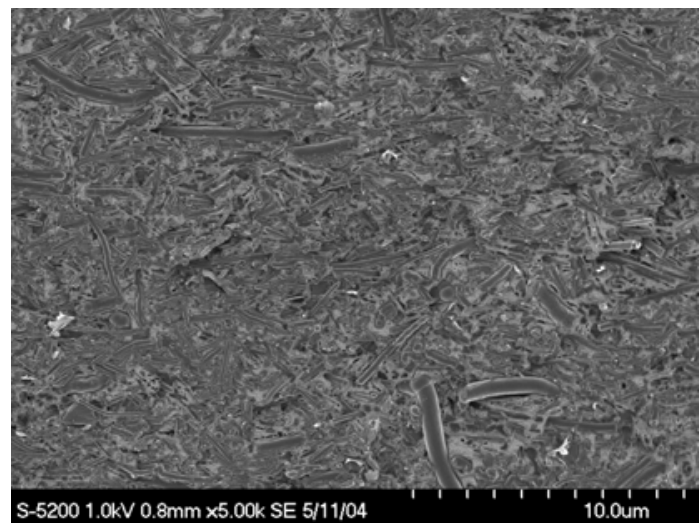

(e)PETI-330/50 wt\% CNF

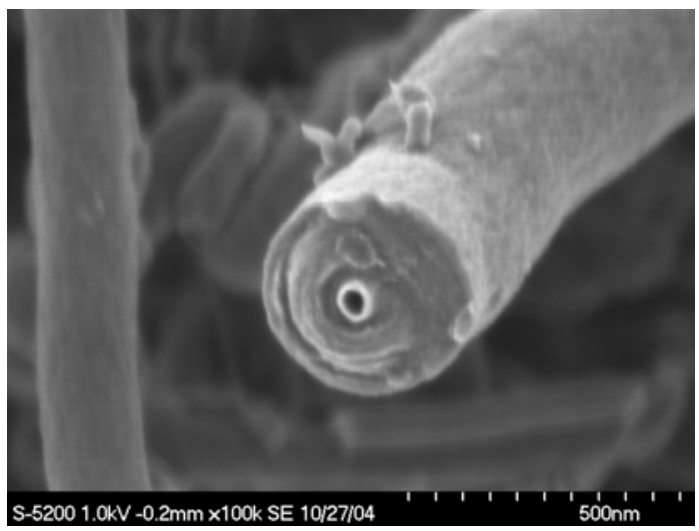

(b) Neat CNF

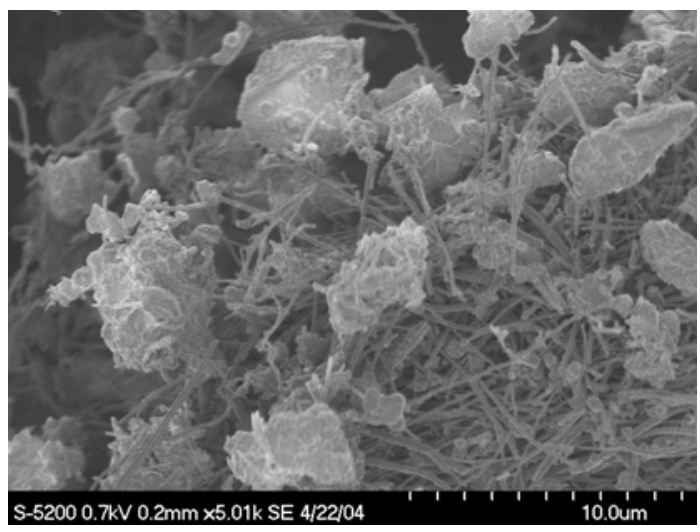

(d) PETI-330/30 wt\% CNF

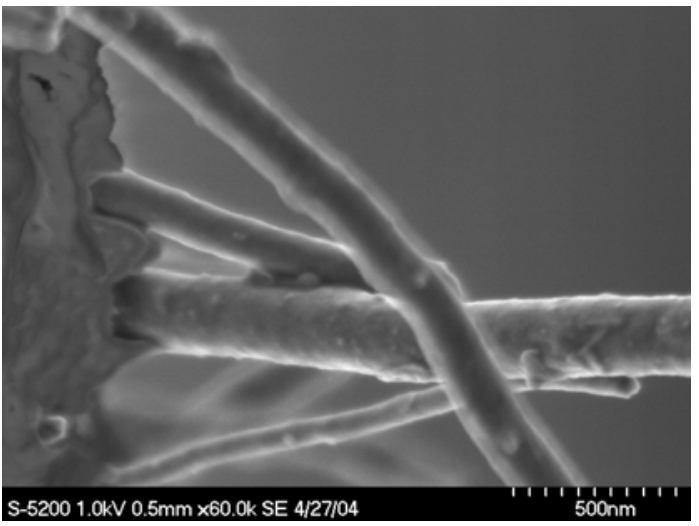

(f) PETI-330/30 wt $\%$ CNF

Figure 1: HRSEM images of neat CNFs $(a-b)$, powdered PETI-330/CNF samples obtained after ball milling $(c-d)$ and PETI-330/CNF obtained from ARES $(e-f)$ 


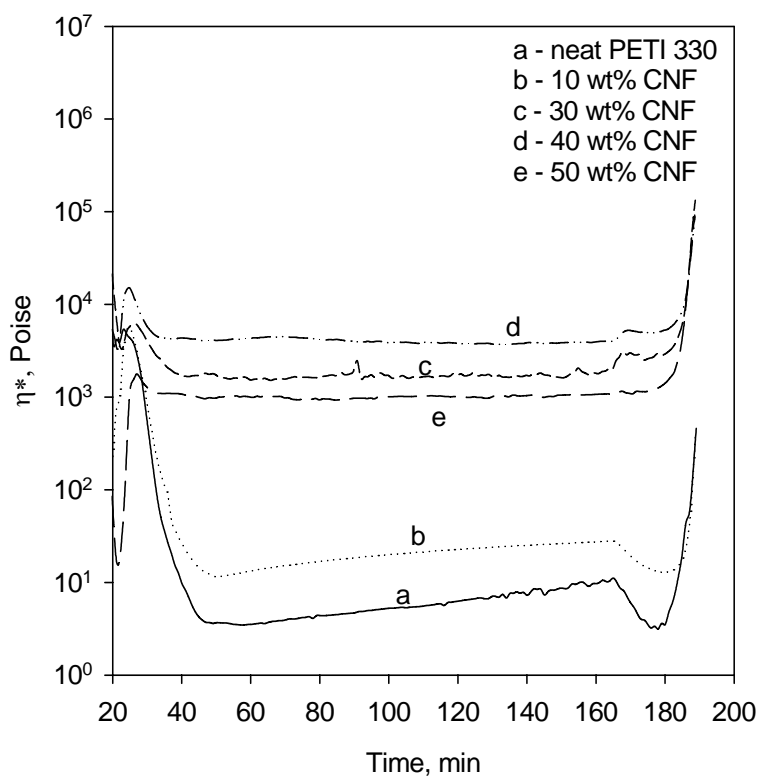

Figure 2: Complex melt viscosity vs. time for PETI-330 with various CNF loadings

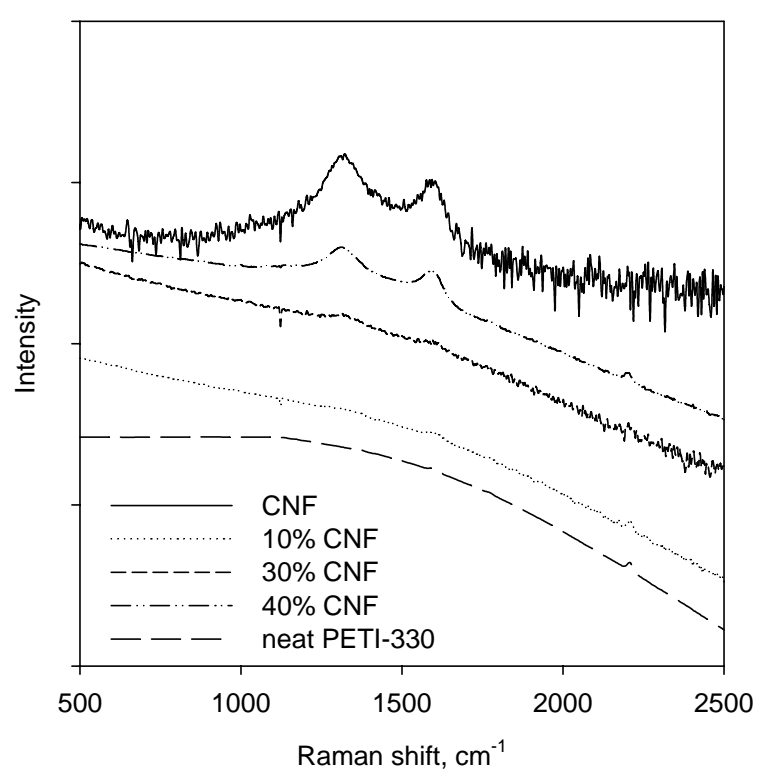

Fig 3: Raman spectra of PETI-330/ CNFs powdered samples

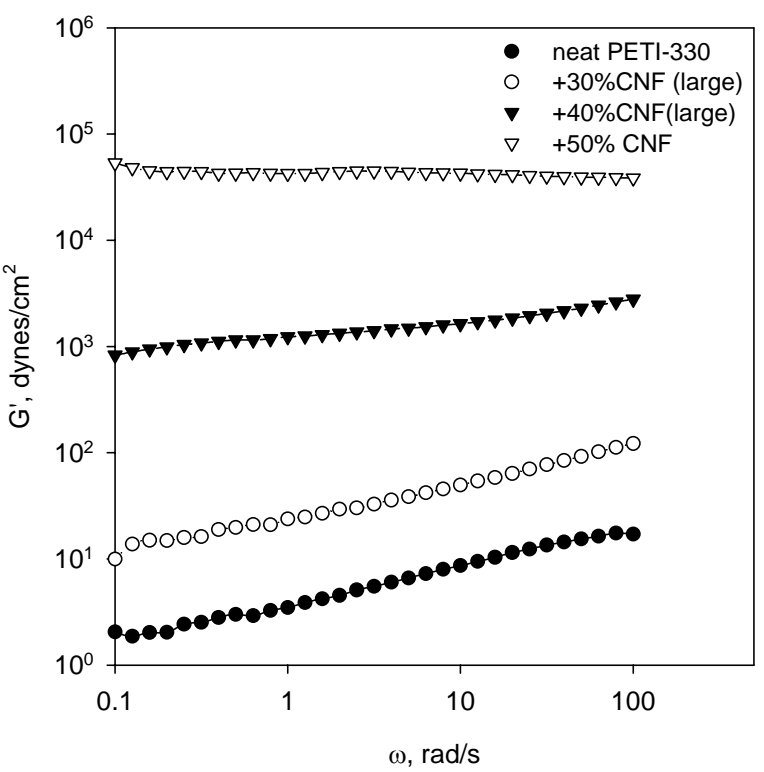

(a)

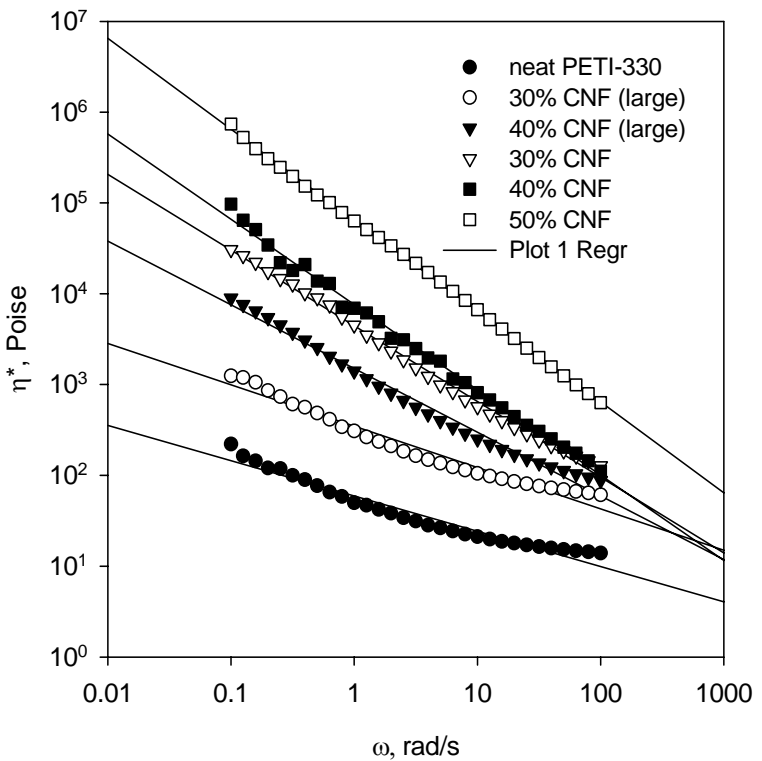

(b)

Figure 4: Frequency vs. a) storage modulus and b) complex viscosity for neat and CNF-filled PETI-330 at $280{ }^{\circ} \mathrm{C}$ and a strain of $10 \%$ 


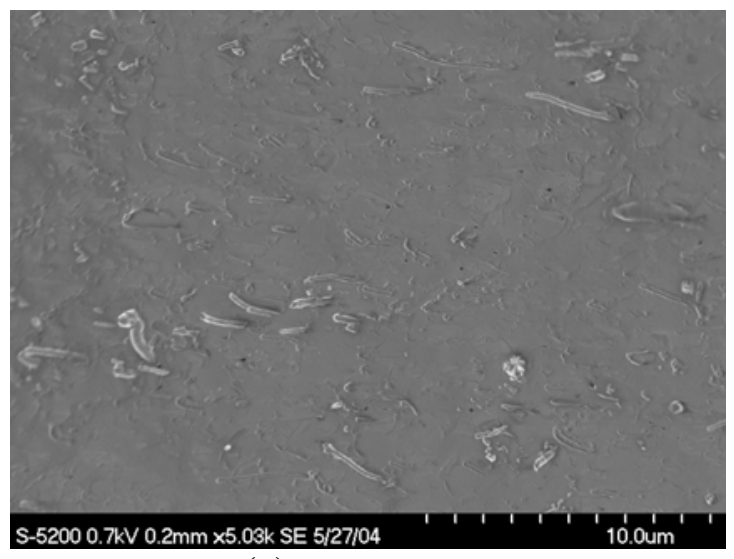

(a)

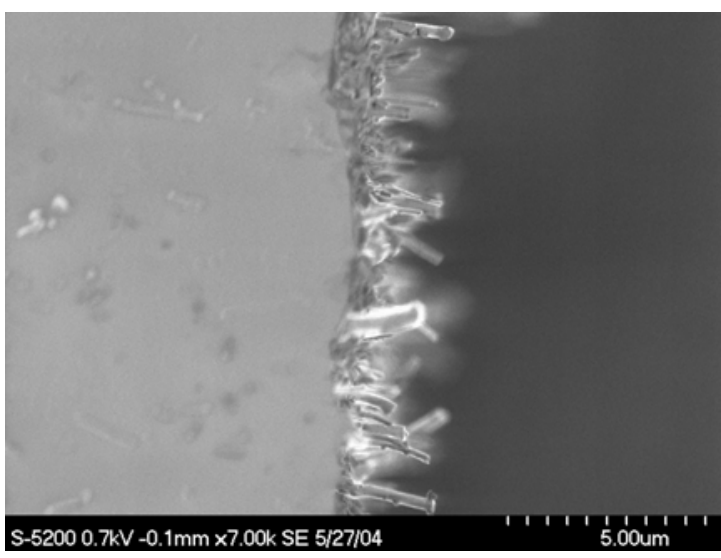

(b)

Figure 5: HRSEM images of PETI-330/30 wt \% CNF samples after extrusion

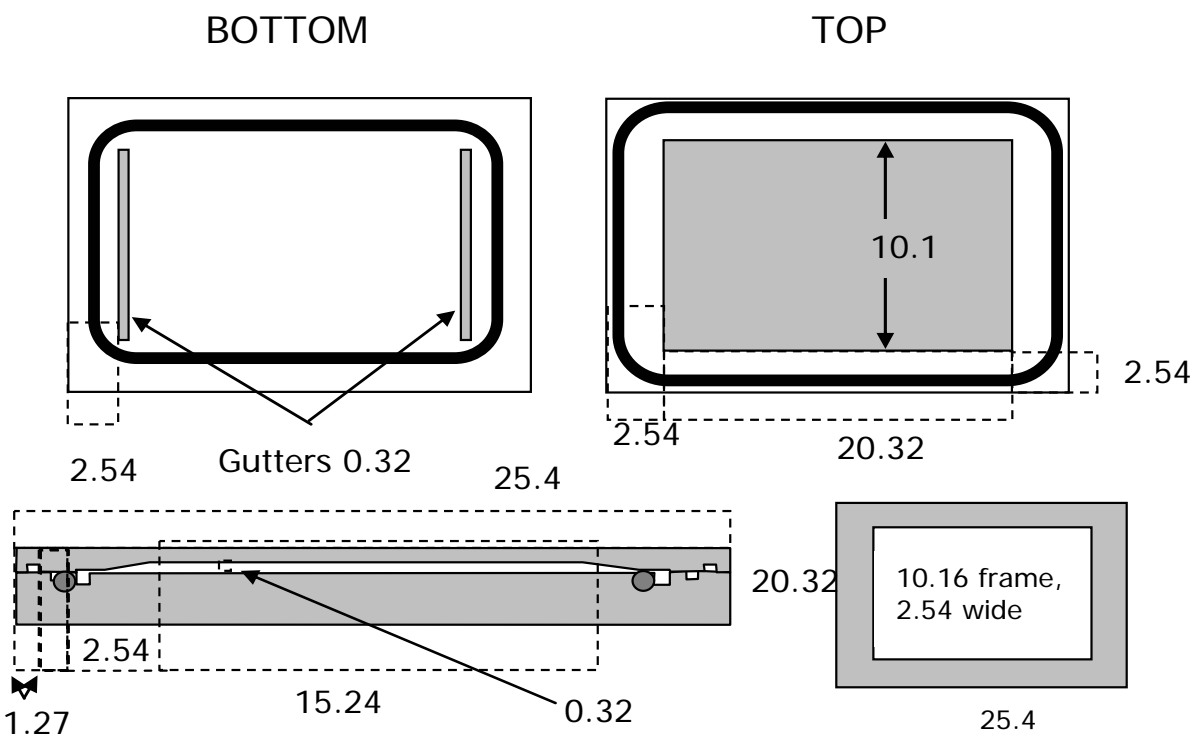

Figure 6: Tool for molding of PETI-330/CNF nanocomposites; dimensions in cm 


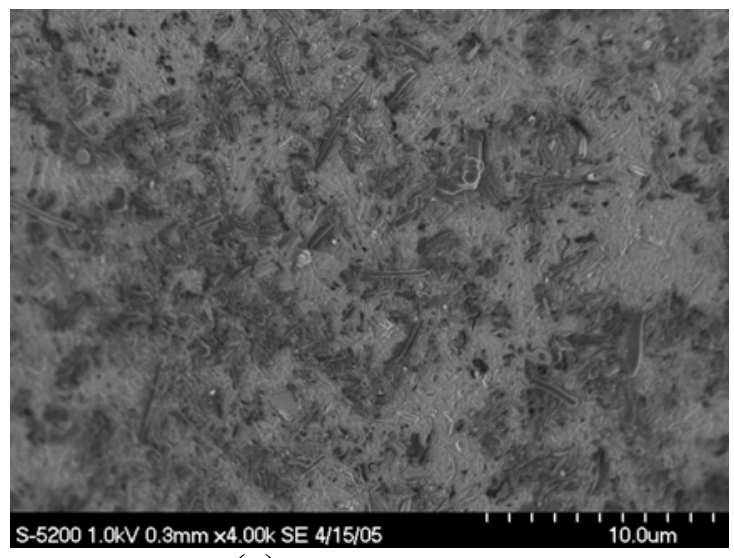

(a)

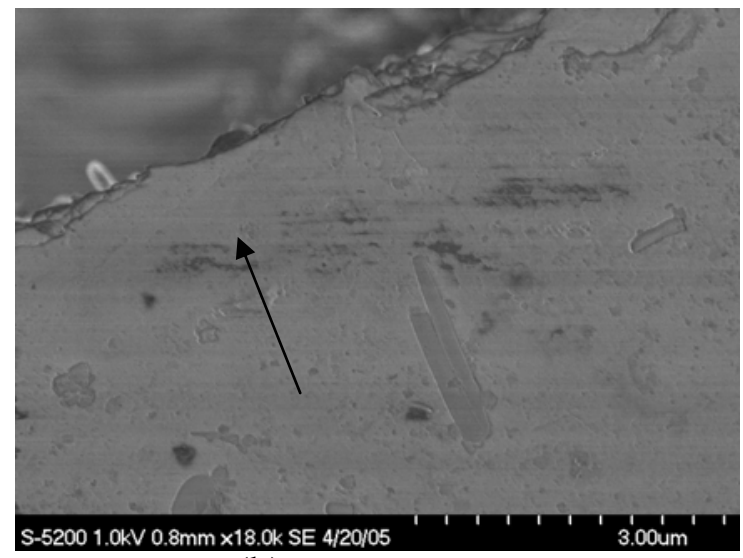

(b)

Figure 7: HRSEM images of injection molded PETI-330 plaque containing $40 \mathrm{wt} \% \mathrm{CNF}$

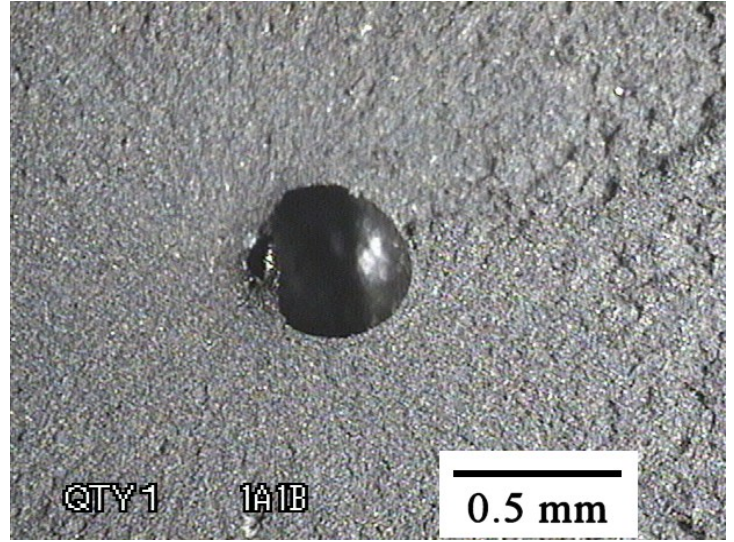

(a)

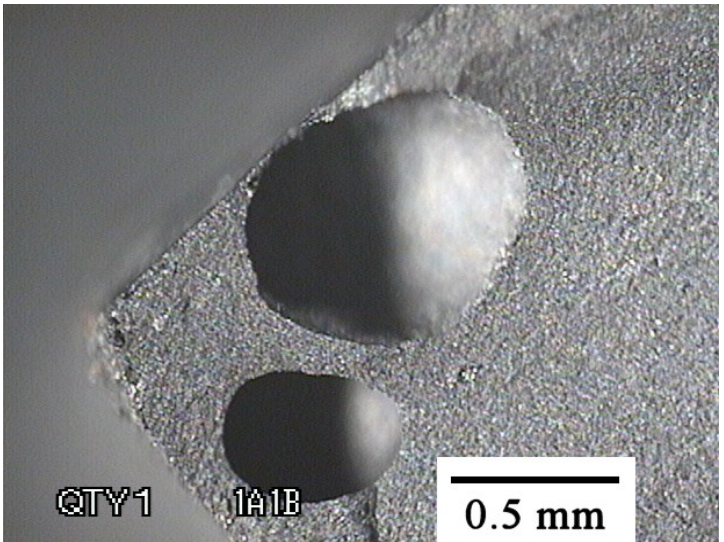

(b)

Figure 8: Optical microscope pictures of defects in fractured PETI-330 samples; a) 30 wt \% CNF and b) $40 \mathrm{wt} \% \mathrm{CNF}$

Table 1: Glass transition temperatures of PETI-330/CNF samples:

\begin{tabular}{|c|c|}
\hline Sample & Tg, ${ }^{\circ} \mathbf{C}$ \\
\hline JFC PETI 330 & 326 \\
\hline $10 \mathrm{wt} \%$ CNF & 328 \\
\hline $30 \mathrm{wt} \% \mathrm{CNF}$ & 330 \\
\hline $40 \mathrm{wt} \% \mathrm{CNF}$ & 333 \\
\hline $50 \mathrm{wt} \% \mathrm{CNF}$ & 332 \\
\hline
\end{tabular}

Table 2: Hardness of PETI-330/CNF plaques: 


\begin{tabular}{|c|c|c|c|}
\hline \multirow{2}{*}{ Sample } & \multirow{2}{*}{$\begin{array}{c}\text { Shore D } \\
\text { hardness }\end{array}$} & Top surface & Bottom surface \\
\cline { 3 - 4 } & 89 & 84.4 & 84.7 \\
\hline Neat & 88 & 78.6 & 78.5 \\
\hline $30 \mathrm{wt} \%$ CNF & 89 & 79.9 & 80.6 \\
\hline $40 \mathrm{wt} \%$ CNF & & & \\
\hline
\end{tabular}

Table 3: Electrical properties of PETI-330/CNF plaques:

\begin{tabular}{|c|c|c|c|c|}
\hline \multirow[t]{2}{*}{ Sample } & \multirow{2}{*}{$\begin{array}{c}\text { Surface } \\
\text { resistivity, } \\
\Omega / \mathbf{c m} \\
\end{array}$} & \multicolumn{2}{|c|}{ Surface resistivity } & \multirow{2}{*}{$\begin{array}{c}\text { Volume } \\
\text { resistivity, } \\
\Omega-\mathrm{cm}\end{array}$} \\
\hline & & $\begin{array}{l}\text { Top } \\
\Omega / \text { sq }\end{array}$ & $\begin{array}{c}\text { Bottom, } \\
\Omega / \mathrm{sq}\end{array}$ & \\
\hline Neat & insulative & $>10^{\frac{1}{12}}$ & $>10^{12}$ & insulative \\
\hline 30 wt \% CNF & $6.13 \times 10^{6}$ & $1.3 \times 10^{5}$ & $5.9 \times 10^{5}$ & $7.8 \times 10^{5}$ \\
\hline 40 wt \% CNF & $1.06 \times 10^{8}$ & $1.8 \times 10^{6}$ & $6.1 \times 10^{6}$ & $2.4 \times 10^{6}$ \\
\hline
\end{tabular}

Table 4: Thermal conductivity of PETI-330/CNF plaques:

\begin{tabular}{|l|c|c|c|c|c|}
\hline \multicolumn{1}{|c|}{ Sample } & $\begin{array}{c}\text { Thickness, } \\
\mathbf{m m}\end{array}$ & $\begin{array}{c}\text { Specific } \\
\text { gravity }\end{array}$ & Cp, J/gK & $\begin{array}{c}\text { Diffusivity, } \\
\mathbf{m m 2 / \mathbf { s }}\end{array}$ & TC, W/mK \\
\hline Neat & 2.417 & 1.305 & 1.199 & 0.140 & 0.219 \\
\hline 30 wt \% CNF & 2.772 & 1.398 & 1.186 & 0.310 & 0.514 \\
\hline 40 wt \% CNF & 2.756 & 1.436 & 1.184 & 0.355 & 0.603 \\
\hline
\end{tabular}

\section{References}

1. E. Hammel, X. Tang, M. Trampert, T. Schmitt, K. Mauthner, A. Eder and P. Potschke, Carbon, 42, 1153-1158 (2004).

2. K. Lozano, S. Yang and Q. Zeng, J. Appl. Poly. Sc., 93, 155-162 (2004).

3. R.J. Kuriger, M.K. Alam, D.P. Anderson and R.L. Jacobsen, Composites, Part A, 33, 53-62 (2002).

4. K. Lozano, J. Bonilla-Rios and E.V. Barrera, J. Appl. Poly. Sc., 79, 125-133 (2001).

5. O.S. Carneiro, J.A. Covas, C.A. Bernardo, G. Caldeira, F.W.J. Van Hattum, J.M. Ting, R.L. Alig and M.L. Lake; Composites Sc. Tech., 58, 401-407 (1998).

6. R.T. Pogue, J. Ye, D.A. Klosterman, A.S. Glass and R.P. Chartoff, Composites: Part A, 29, 1273 (1998).

7. C.A. Cooper, D. Ravich, D. Lips, J. Mayer and H.D. Wagner, Composites Sc. Tech., 62, 1105 (2002).

8. V.I. Merkulov, D.H. Lowndes, Y.Y. Wei, G. Eres and E. Voelkl, Appl Phys Lett, $\underline{76}(24), 3555$ (2000).

9. M. Endo, Y.A. Kim, T. Hayashi, Y. Fukai, K. Oshida, M. Terrones, T. Yanagisawa, S. Higaki and M.S. Dresselhaus, Appl Phys Lett, $\underline{80}$ (7), 1267 (2002). 
10. D.D.L. Chung, O.I. Fisun, A.N. Goltsov, V.N. Kadeansev and Y.K. Alexandrov, http://www.telecomlab.gr/2002/oct/rhodes/pap3rs/N\%20069\%20_p523\%20-\%20p531_.pdf 11. J.G. Smith Jr., J.W. Connell, P.M. Hergenrother, R. Yokota, J.M. Criss, Soc. Adv. Mat. Proc. Eng. Ser.; 47, 316 (2002).

12. J.G. Smith Jr., J.W. Connell, P.M. Hergenrother, L.A. Ford, J.M. Criss, Macromol. Symp.; $\underline{199}, 401$ (2003).

13. J.W. Connell, J.G. Smith Jr, P.M. Hergenrother, J.M. Criss, Int. SAMPE Tech. Conf. Series, 35, Dayton, OH (2003).

14. Z. Konya, J. Zhu, K. Niesz, D. Mehn, I. Kiricsi, Carbon, 42, 2001 (2004).

15. Y.A. Kim, T. Hayashi, Y. Fukai, M. Endo, T. Yanagisawa, M. Dresselhaus, Chem. Phys. Lett., 355(3-4), 279 (2002).

16. Y.B.Li, B.Q. Wei, J. Liang, Q. Yu and D.H. Wu, Carbon, 37, 493 (1991).

17. K. Awasthi, R. Kamalakaran, A.K. Singh and O.N. Srivastava, Int J Hydrogen Energy, 27, 425 (2002).

18. J.Y. Huang, H. Yasuda and H. Mori, Chem. Phys. Lett., 303(1-2): 130 (1999).

19. N. Pierard, A. Fonseca, Z. Konya, I. Willems, G. van Tendeloo and J.B. Nagy, Chem. Phys. Lett.; 335 (1-2): 1 (2001).

20. N. Pierard, A. Fonseca, J.F. Colomer, C. Bossuot, J.M. Benoit, G. van Tendeloo and J.B. Nagy, Carbon; 42, 1691 (2004).

21. S. Kumar, T. Uchida, T. Dang, X. Zhang and Y. Park, Soc. Adv. Mat.Proc. Eng. Ser., $\underline{49}$, (2004).

22. J. Sandler, A.H. Whindle, P. Werner, V. Alstadt, M.V. Es and M.S.P. Schaffer, J. Mater. Sci., 38, 2135 (2003).

23. M. Cadek, B.L. Foulgoc, J.N. Coleman, V. Barron, J. Sandler, M.S.P. Shaffer, A. Fonseca, M.V. Es, K. Schulte and W.J. Blau, AIP Conference Proceedings: Structural and Electronic Properties of Molecular Nanostructures, 633, 562 (2002).

24. R.D. Patton, C.U. Pittman, L. Wang and J.R. Hill; Composites: Part A, 30, 1081 (1999).

25. S. Ghose, K.A. Watson, D.C. Working, D.M. Delozier, E.J. Siochi, J.W. Connell, Composites: Part A, (accepted March 2005).

26. http://www.eng.auburn.edu/department/ee/ADCFCT2001/ADCFCTabstract/013.htm

27. C. Stephan, T.P. Nguyen, B. Lahr, W. Blau, S. Lefrant, O.J. Chauvet, Mater. Res., 17(2): 396 (2002).

28. http://www.calce.umd.edu/general/Facilities/Hardness_ad_.htm

29. J.G. Smith, Jr., K.A. Watson, J.W. Connell, D.M. Delozier, P.T. Lillehei, Y. Lin, B. Zhou

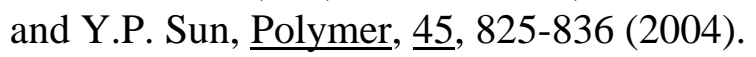

